\title{
Corrigendum: Using genetics to prioritise headwater stream fish populations of the Marico barb, Enteromius motebensis Steindachner 1894, for conservation action
}

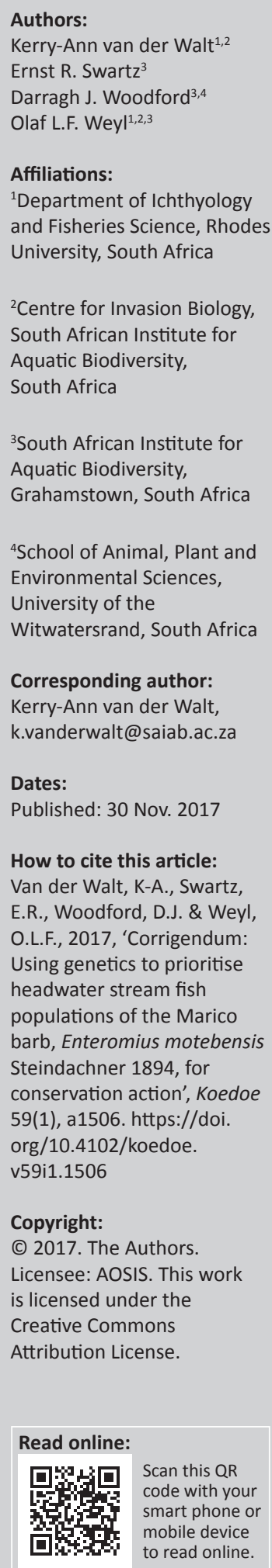

Scan this QR code with your smart phone or

In the version of this article initially published, Kerry-Ann van der Walt's and Darragh J. Woodford's second affiliation, and Olaf L.F. Weyl's first affiliation was omitted. The initials for Darragh J. Woodford and Olaf L.F. Weyl was also omitted.

The author list and affiliations are hereby corrected to:

Authors:

Kerry-Ann van der Walt ${ }^{1,2}$

Ernst R. Swartz ${ }^{3}$

Darragh J. Woodford ${ }^{3,4}$

Olaf L.F. Weyl $1^{1,2,3}$

\section{Affiliations:}

${ }^{1}$ Department of Ichthyology and Fisheries Science, Rhodes University, South Africa ${ }^{2}$ Centre for Invasion Biology, South African Institute for Aquatic Biodiversity, South Africa ${ }^{3}$ South African Institute for Aquatic Biodiversity, Grahamstown, South Africa

${ }^{4}$ School of Animal, Plant and Environmental Sciences, University of the Witwatersrand, South Africa

The errors have been corrected in the PDF version of the article. The corresponding author apologises for any inconvenience that this omission may have caused. 